\title{
Study on the construction of project Management's ecological science and technology innovation capacity
}

\author{
Zhen $\mathrm{Li}^{1, \mathrm{a}}$ \\ ${ }^{1}$ School of Civil Engineering and Architecture, Wuhan Polytechnic University, People's Republic \\ of China \\ a66994752@qq.com
}

\begin{abstract}
Keywords: Project management; Environment; Eco-technological innovation; Enterprises; Laws and regulations

Abstract. Both the construction of ecological civilization and the project management are widely concerned by people. This paper's purpose is to analyze the relationship between project management and ecological civilization construction, and research how to strengthen the construction of ecological technology innovation capacity. It tells us that the capacity of ecological technology innovation can be improved from the laws, regulations, market conditions and the government's guidance. The article uses the comparative analysis and has a good reference to the development of enterprises.
\end{abstract}

\section{Introduction}

The complexity of the project determines the project management's difficulty. The project management involves a wide range of every project management activities which must be carried out under certain natural conditions, and are influenced by natural conditions, including resources, climate, geology and topography etc. From the engineering design to the project consumption, every stage of the project management activities needs to be considered and analyzed. The relationship between project management and ecological civilization construction is widely concerned by the society.

\section{The relationship between project management and ecological civilization construction}

For engineering projects, enterprises tend to pay more attention to their economical efficiency. When the construction of ecological civilization is more and more concerned by the society, the social attributes of project management is becoming more and more important to the enterprises and the public. Ecological civilization is the result of the harmonious coexistence between the man and the nature, which is the result of the transformation of human nature and the achievement of personal purpose. At present, our country is in the key period of urbanization, and the large-scale projects are in full swing. ${ }^{[1]}$ These projects have huge and irreversible impact on the environment. The correct treatment of project management and the construction of ecological civilization has important practical and social significance. Our country is gradually changing from the extensive economic development mode to the environment friendly economic mode.

Scientific and technological innovation is the most direct impetus to change the social situation. ${ }^{[2]}$ At present, science and technology to engineering projects as the carrier, with unprecedented speed and power to change the world we live in. However, as the starting point of technological innovation, it is often difficult to achieve an organic balance between economic interests and environmental protection. Therefore, with the continuous development of science and technology, the two sides of technology become more and more obvious. On the one hand, technological innovation is changing the world, providing a more convenient way of life for human beings. On the other hand, technology also makes the human living environment face great risks and threats.

To sum up, project management and ecological civilization construction are inseparable. The construction of ecological civilization is inseparable from the scientific and technological innovation. ${ }^{[3]}$ In order to realize the win-win situation of project management and ecological civilization construction, we must make the necessary restriction on scientific and technological innovation. We should establish the ecological values in science and technology development, promote ecological 
technology, and seek the harmonious development of human and the nature. This is not only the new requirements of the ecological civilization construction, but also the important achievements of the scientific development concept.

\section{Analysis of ecological science and technology innovation ability}

Eco technology innovation refers to bringing new products and processes with the value of goods for customers and reduce the impact of technological innovation on the environment. Different from other innovation, ecological science and technology innovation has a positive external effect and reduce the product cost of external environment. According to the research abroad, the scientific and technological innovation ability of enterprises is mainly affected by three factors. They are laws and regulations, market and enterprises.

The effective laws and regulations can promote the improvement of the enterprise's ability in ecological science and technology innovation ability

Laws and regulations are important means to deal with market failure. It is an important constraint to avoid the environmental costs imposed on society by enterprises. Effective laws and regulations can strengthen the enterprise's ecological innovation motivation, encourage enterprises to carry out technological innovation activities. However, the premise of this logic is that the cost of violation of laws and regulations is high enough. If the interests of innovation can not offset the cost of technological innovation, this win-win situation is unstable. The influence of laws and regulations on the innovation of enterprises' ecological science and technology is showed from three aspects.

Firstly, strong laws and regulations can promote enterprises to continuously strengthen the construction of ecological science and technology innovation capacity. ${ }^{[4]}$ The intensity of laws and regulations is usually manifested in the control of pollution indicators, the more clear the quantitative indicators, the greater the intensity of laws and regulations, the greater the risk of corporate environmental laws and regulations. The greater illegal risk enterprises are facing, the more they will increase the investment in science and technology.

Secondly, good policy instruments can stimulate the enthusiasm of enterprise's ecological innovation. Thirdly, predictability of regulation policies in the future will have a positive impact on innovation in science and technology. If the policy continues to become more stringent, the environment friendly enterprises will be more competitive.

\section{The market of effective competition is positively related to the science and technology innovation ability of enterprises}

Classical economic theory believes that the product is determined by market supply and demand. ${ }^{[5]}$ As the provider of innovation ability of science and technology, the enthusiasm of enterprise innovation is closely related to the market demand. The factors that affect the market's demand include: market's structure, customer's demand and potential customer interest.

Market's structure is one of the key factors for innovation. Market's structure can be measured by the degree of competition or market concentration. With less the uncertainty of the future business of the enterprise, the enterprise will have more energy in the research process. At the same time, the higher the degree of concentration, the less likely they muddle through. Therefore, enterprises must increase investment in science and technology to reduce illegal risk. Another view is that, due to the lack of competition, the high market concentration leads to enterprises' more lazy and thus hindering scientific and technological innovation.

The customer's demand is one of the driving forces of enterprise innovation behavior. Classical economists believe that products are determined by supply and demand. As the society is more and more concerned about the green attributes of the product, it will be more likely to be loved by consumers, so as to obtain a higher market share and improve the ability of innovation. Therefore, the consumption habit of customers is also an important driving force for a enterprise to improve the ability of ecological science and technology innovation. 
Potential customer interest is the reserve power of scientific research input. Potential customers are the important goals of the future development of an enterprise. Taking into account the interests of potential customers helps to understand the potential market, and promote the success of enterprises in the market. If the enterprise can meet the interests of potential customers, it is easier to open up the new market.

\section{The internal factors of enterprises have a direct impact on the innovation ability of science and technology}

Both the regulations and the market environment are the external environment for enterprises. In addition to the impact of the external environment, the success depends on the enterprise's own conditions. The internal factors include development strategy, asset structure and research capabilities. Enterprise development strategy is an important factor that affects enterprise investment decision. Business and investment activities are carried out around the strategic objectives of enterprises. Therefore, the ecological technology innovation ability into the enterprise development strategy, can make enterprise decision-making pay more attention to environmental protection, and improve the awareness of environmental protection, thereby enhancing the technological innovation ability of the enterprise ecosystem.

The size of an enterprise is also an important factor affecting the scientific and technological innovation. The larger the size of an enterprise is, the more investment can be used in the scientific research. At the same time, enterprises own the stronger the ability to withstand the risk of failure in the research, and therefore dare to increase investment in ecological science and technology innovation. The scientific research ability of enterprises will also affect their innovation. It is necessary for enterprises to have rich management experience and high-level researchers.

\section{Current situation of project management and ecological civilization construction in China}

Although the construction and development of China's project management has made great progress, there are still a lot of problems, compared with the requirements of ecological civilization.

The development of project management market is not balanced. The gap between different industries is large, and the regional construction standards are not same. The economically underdeveloped areas often use the expense of the environment in exchange for economic development. It's not only the result of government's performance considerations, but also the lack of environmental awareness of enterprises.

Construction of the project management system needs to be further improved and the implementation of the system should be more stringent. Project management system is an important guarantee to improve the quality of the project and the level of management. Although China has done a lot of work to improve laws and regulations, but there are still many imperfect places. Some laws, regulations and policies of the system lags behind the actual market demand. Some laws and regulations of construction project management has not been updated in a timely manner.

Technical level of project management activities is not high. Science and technology are the most important productive forces. ${ }^{[6]}$ Only by constantly carrying out scientific and technological innovation, and using new products and technologies in the practical activities, can we further improve the quality of project management. China's science and technology innovation is insufficient, and the application of science and technology has been lagging behind, which is mainly reflected in that the system of argumentation before the start of the project is not enough. Furthermore, the preliminary investigation is not sufficient too. This not only caused a great waste of resources, but also resulted in irreversible damage to the environment.

\section{How to strengthen the construction of eco-technology innovation capacity in project management}

First, it should strengthen the leadership of government from the top-level. Environmental protection is the long-term interests of enterprises. But the motivation to pursue the short-term interests will lead 
to the fact that enterprises are reluctant to increase investment in ecological technology innovation. It requires that the government should give enterprises correct guidance by the formulation of policies. The policies ought to be forward-looking and predictability, promote enterprises' construction of eco-technology innovation in the production. Enterprises are the main body in the development of ecological science and technology. The government should clear the responsibility of enterprises through legislation, and increase the cost of enterprises' illegal activities.

Second, laws and regulations should be perfected and mandatory standards should be set to promote the ecological transformation of project management. Although our country has promulgated many rules and regulations in project management and environmental protection, the qualitative standard to test execution is still imperfect. Therefore, we should accelerate the process of making mandatory standards, and define these standards by laws and regulations to ensure the effective implementation of industry standards.

Third, the investment in scientific research policy support and incentives should be increased to improve the enthusiasm of enterprise's ecological science and technology innovation. Different stimulation methods can promote the construction of ecological technology innovation in different degrees. The government should use various means of support and encouragement of science and technology innovation in project management process, such as increasing policy support, giving priority to the development of ecological technology innovation, and encouraging enterprises to raise the expenditure of the ecological technology innovation. In the premise of ensuring national security, the advanced management experience should be introduced, and accelerate the process of scientific and technological innovation.

\section{Conclusion}

The development of ecological technology construction and innovation is the important driving force to promote the construction of ecological civilization. Establishing the view of ecological civilization and raising the eco-technology innovation is the only way to slow down the sustained pressure on resources and environment, which is conducive to the growth of the healthy economy. All the Chinese construction enterprises should pay more attention to this problem.

\section{References}

[1] Brunner Meler, S B Cohen: Determinants of environmental innovation in US manufacturing industries. Journal of environmental Economics and Management. 2003(45)

[2] Fussler, C P James: Drivng eco innovation a break through discipline for innovation and sustainability. Financial Times Prentice Hall.1997(5)

[3] Horbach: Determinants of environmental innovation new evidence from German panel date sources. Research Policy. 2008(2)

[4] Mazzant I M, Zobol I R: Examinning the factors influencing environmental innovations. Working Paper series 2006

[5] Zhou Shuliang, Wang Weiguang: Scientific and technological innovation and upgrading of industrial structure. World management. 2001(5)

[6] Zhu hongliang: Research on the interactive relationship between engineering construction standards and laws and regulations. Scientific progress and Countermeasures. 20009.26(11) 